\title{
$\checkmark$ THE MEDICAL MANAGEMENT OF OBLITERATIVE ARTERIAL DISEASE OF THE LEGS
}

\author{
By Robert Semple, M.D., M.R.C.P. \\ First Assistant, Medical Unit, The Middlesex Hospital
}

\section{Introduction}

Obliterative arterial disease of the legs is commonly arteriosclerotic in origin, but thromboangiitis obliterans, primary bland thrombosis and other arteriopathies are also included under this heading. The nature of the lesion makes little difference to medical management, although the question of surgical treatment and the prognosis must obviously be affected. The site of the arterial obstruction, however, is of some importance in deciding on treatment; for example, the introduction of drugs into the femoral artery would be pointless if the main obstructive lesion was in the iliac artery or in the aorta. In arteriosclerotic disease of the lower limb occlusion of the femoral artery accounts for more than half of the cases. The popliteal and iliac arteries are equally affected and together account for nearly one-third. In the remainder the abdominal aorta or the tibial vessels are involved. The exception to these rules is in diabetic arterial disease in which the vessels of the lower leg and foot are most affected (Semple, 1953).

In considering the management of these patients certain important principles must be remembered: (I) The arterial disease is in most cases generalized and the signs and symptoms in the legs are only one manifestation. McDonald (1953) found that nearly 40 per cent. of his patients with intermittent claudication had clinical or electrocardiographic evidence of ischaemic heart disease. Wright (1940) has pointed out that there is little advantage in prolonging the claudication distance if the patient is going to die of ischaemic heart disease as a result.

(2) Medical treatment is not curative in this condition, but essentially palliative, as occluded arteries cannot be reopened, although Wright, et al. (1953) have produced evidence that anticoagulants may stimulate recanalization of recently thrombosed arteries in the rabbit.

(3) Carefully planned medical treatment and advice may provide great symptomatic relief and may prolong life and health.
Medical management may be subdivided into three main parts:

i General measures.

ii The relief of intermittent claudication.

iii The prevention of gangrene.

\section{General Measures}

These are directed at any associated condition. Some of these patients are overweight and reduction of this may be followed by great improvement. Any anaemia should be appropriately treated and the presence of polycythaemia rubra vera should not be overlooked, as reduction in the number of circulating red cells will greatly help the vascular condition. Diabetes should be brought undero control if present, and any cardiac condition shouldo be treated. These patients should stop smoking There is no good evidence that intermittent? claudication will be benefited, but it has been shown that the blood flow through the hands and feet is diminished by smoking (Shepherd, I95I); where the circulation is already precarious, this is obviously undesirable. In some cases a period of two or three weeks' rest in bed may be beneficial.

\section{Relief of Intermittent Claudication}

There are two possible methods of approach to this problem: to improve the blood supply to the active muscles or to lessen their demand for blood by reducing the work they have to do.

Various means have been used to increase the blood supply to the muscles, including drugs and physical methods; the great number of methods which have been advocated probably indicates the inefficacy of most of them.

\section{Physical Methods}

Several of these methods are available, but their actual value is doubtful. Intermittent venous occlusion has been widely recommended, but recent experimental work on cats (Thompson and Vane, I95I) indicates that the increase in blood flow after occlusion is transitory and that the net result is a decrease in the circulation. Hamilton and Wilson (1952) in a clinical trial considered that any improvement following a period of inter- 
mittent venous occlusion was probably due to the enforced rest in bed and personal clinical impressions are in agreement with this view. Intermittent suction in the Paevex boot has little to recommend it; both these methods may lead to venous thrombosis which may precipitate gangrene.

Buerger's exercises or Allen's modification have the advantage that they do no harm. Their positive value is more doubtful, but they at least make the patient feel that something is being done for him, which is not unimportant in a condition for which specific effective treatment is often lacking.

\section{Drugs}

Many have been suggested for this purpose, but Kissin, et al. (I95I), in controlled acute experiments using drugs and placebos, found that nitroglycerine, papaverine, ethyl alcohol, pancreatic extracts, histidine and ascorbic acid were ineffective in increasing the claudication distance, although aminophylline intravenously increased exercise tolerance by 42 per cent. Shepherd (1950), using an ergograph and measuring calf blood flow before and after exercise, found no benefit from pancreatic extract or tetraethyl ammonium bromide. More recently Hamilton and Wilson (1952) found that oral nitrites, subcutaneous adrenaline and intravenous nicotinic acid, tetraethyl ammonium, tolazoline hydrochloride, dihydroergotamine or pancreatic extract did not alter the claudication distance. On a long-term basis these authors found alpha-tocopherol, tolazoline, testosterone, papaverine and aminophylline to be equally ineffective. Douthwaite and Finnegan (1950) and Goodwin and Kaplan (195I) considered that some patients were improved by Priscol (tolazoline hydrochloride) in doses of 25 to $100 \mathrm{mgm}$. thrice daily. It has been claimed that alpha-tocopherol given over a period of at least three months in a daily dose of $400 \mathrm{mg}$. results in significant improvement (Ratcliffe, 1949), although this is denied by Hamilton, et al. (1953). It has been claimed that the injection of vasodilator drugs into the femoral artery on the affected side at intervals of a week over a few weeks is followed by significant improvement in intermittent claudication (Mufson, 1948; Edwards, et al., 1952). Personal experience with all these drugs and methods has been disappointing and it is possible that improvement reported after the use of certain drugs is no more than would have resulted from conservative treatment and the passage of time.

The second method of approach to the symptom of intermittent claudication is to lessen the demand for blood by the calf muscles. Lewis and his colleagues (Lewis, et al., I93I) showed that halving the rate of contractions of muscles exercising under ischaemic conditions doubled the time taken for pain to appear. Naide (1949, I950a and b) studied the walking habits of 30 patients with intermittent claudication. He found that, although these patients thought they were walking more slowly, they did not, in fact, slow down till the pain came on. By slowing their walking speed from an average of 110 to 120 steps per minute to 90 to 105 the onset of pain was delayed, in some cases indefinitely. It is difficult to teach a man of middle age and fixed habits to slow his walking speed, but once he achieves this he is often surprised how far he can walk without pain. One physician advises these patients to walk with their hands in their pockets and this is often effective. Naide found that a shorter step and holding the knee stiff also helped. The work of the calf muscles may also be reduced by fixation of the ankle joint with a check iron (Learmonth and Slessor, 1952).

In summary, intermittent claudication may be helped by measures directed at associated conditions such as obesity and anaemia and by measures designed to relieve the calf muscles of work during walking. Considerable spontaneous improvement may occur, especially following 8 sudden thrombotic episode, but treatment by physical methods and vasodilator drugs is relatively ineffective.

\section{The Prevention of Gangrene} Care of the Feet

Barker (I935) studied II 5 cases of arteriosclerotic gangrene of the toes. He found that this followed a minor therapeutic procedure such as removing a toenail or a corn, applying adhesive tape or incising an abscess in 39 per cent. of cases. In 17 per cent. gangrene followed minor local trauma. This emphasises the well-known fact that scrupulous care of the feet is vitally important in these patients. 'They should be instructed to wash the feet daily, to dry them carefully, especially between the toes, and to apply a simple dusting powder. Joslin (1948) remarks that, in diabetics, if the feet are kept as clean as the face, gangrene and infections will seldom occur. Hard, cracked skin under the heels and toes may be softened by the inunction of lanoline. The feet should be kept as warm as possible by soft, long woollen socks which should be changed daily. The shoes should be easy fitting and comfortable. Minor injuries, abrasions and blisters must be avoided and they may be told to treat their feet " as if they were made of Dresden china'! The toenails should be carefully cut straight across, paring of corns with old razor blades and such tools should be forbidden and, if necessary, treatment by a chiropodist should be arranged. Interdigital fungus infection should be treated. Prolonged 
standing should be avoided and the local application of heat such as by hot-water bottle may be dangerous.

\section{Vasodilator Drugs}

These probably have a more useful part to play than in the treatment of intermittent claudication. Several of these drugs increase cutaneous blood flow, although this increase may be at the expense of the deep tissues. The most useful drug at the moment appears to be tolazoline hydrochloride (Priscol), which has an adrenolytic action as well as a direct antispasmodic action on the blood vessel wall (Grimson, et al., 1948). 'By injection it causes an increase in blood flow through the hand and foot (Lynn, I950); it is probably less effective given orally, but Douthwaite and Finnegan (1950) found a definite vasodilatory action in peripheral vessels. Goodwin (1952) considers that the initial improvement in the blood flow following oral tolazoline is not always maintained and that the total effect is less than that of lumbar sympathectomy. Personal experience is that tolazoline in doses of 25 to $75 \mathrm{mg}$., according to tolerance, thrice daily, is a drug which has a use in such cases, although the effect is unpredictable and often disappointing. Other more recent drugs recommended are Ronicol (3-hydroxymethylpyridine) (Samuels and Padernacht, I950) and the hydrogenated alkaloids of ergot (Kappert and Hadorn, 1950), but it is unlikely that these will be any more effective.

\section{The Management of Impending Gangrene}

Rest is the most important measure where the nutrition of the limb is precarious. There is some evidence that the maximum blood flow through a limb is obtained when the body is horizontal but the limb dependent (Wilkins, et al., 1950), but to keep a gravely ischaemic limb dependent is to court disaster from venous stagnation and thrombosis. It is probable that the horizontal position is safer. The affected limb may be kept warm by cotton wool coverings; the blankets should be kept off it by means of a cradle. The not uncommon practice of exposing such a limb to the air is, I think, a bad one because of the resulting local vasoconstriction and intense local discomfort and pain. It is dangerous to apply local heat in any form. Reflex heating by warming the rest of the body with hot-water bottles or a cage is a useful measure. Passive exercises are useful to prevent venous stagnation and scrupulous attention must be paid to the toilet of the affected extremity. Vasodilator drugs may be used as detailed above and, when a sudden arterial occlusion has occurred, the use of the anticoagulants may be considered. Following acute arterial occlusion, the intra-arterial injection of tolazoline has been suggested by Lynn (1950). This may be a useful emergency measure and is probably more effective and less dangerous and unpleasant than procaine infiltration of the sympathetic chain. When gangrene has become established, management is essentially the same as for threatened gangrene. Antibiotics may be used to prevent spreading infection; the gangrenous foot should be kept dry, and irritant or antiseptic dressings avoided. Analgesics may be required for the relief of pain. The question of operative removal of the gangrenous area should be decided in consultation with the surgeon.

\section{Conclusion}

Some forms of obliterative arterial disease may be more suitably treated surgically. Local obstructive arterial lesions may be amenable to direct attack by arterial grafting or disobliterative endarterectomy; when local nutrition is threatened, lumbar sympathectomy may be called for; amputation may be necessary in established gangrene and section of the tendo Achilles may be of benefit to some patients with intermittent claudication. It follows that close liaison must be maintained between physician and surgeon to secure moso benefit for these unfortunate sufferers. Surgicad measures must, however, be planned against tho background of the patient's general condition an in particular of the state of the coronary arteries? This general assessment of the patient is the duty of the physician.

\section{BIBLIOGRAPHY}

BARKER, N. W. (1935), Ұ. Amer. med. Ass., 104, 2147 DOUTHWAITE, A. H., and FINNEGAN, T. R. L. (1950), Brit. med. F., 1, 869.

EDWARDS, J." W. L., JONES, N. B., MCCONNELL, R. B., PEMBERTON, H. S., and WATSON, D. C. (1952), Ibid., ii, 808 .

GOODWIN, J. F., and KAPLAN, S. (1951), Ibid., i, 1102.

GOODWIN, J. F. (1952), Brit. med. Bull., 8, 371.

GRIMSON' $K$ S REARDON, M. J. MARZONI, F. A., and HENDRIX, J.' P. (1948), Ann. Surg., 127, 968.

HAMILTON, M., and WILSON, G. M. (1952), Quart. f. Med., $22,169$.

HAMILTON, M., WILSON, G. M., ARMITAGE, P., and BOYD, J. T. (r953), Lancet, i, 367.

JOSLIN, E. P. (1948)' 'Diabetic Manual,' Henry Kimpton, London. KAPPERT, A., and HADORN, W. (1950), Angiology, i, 520.

KISSIN, M., STEIN, J. J., and ADLEMAN, R. J. (I95I), Ibid. ISSIN, $M$

LEARMONTH, J., and SLESSOR, A. J. (1952), Brit. med. Bull. 8, 375; PICKERING, G. W, and ROTHSCHILD, $P$. (I931), Heart, 15, 359.

CYNN R

MCDONALD, L. (1953), Brit. Heart f., 15, 101.

MUFSON, I. (1948), Ann. intern. Med,, 29, 903

NAIDE, M. (1949), Trans. Coll. Physicians, Philadelphia, 17, 145.

NAIDE, M. (1950), F. Amer. med. Ass., 143, 968.

NAIDE, M. (1950), Penn. med. F., 53, 1283.

RATCLIFFE, A. H. (1050), Lancet, ii, 1128 .

SAMUELS, S. B., and PADERNACHT, E. D. (1950), Angiology, 1,236 .

SEMPLE, R. (1953), Lancet, 1,1064

SHEPHERD, J. T. (1950), Brit. med. Y., ii, 1413

SHEPHERD, J. T. (1951), Ibid., ii, 1007.

THOMPSON, J. E. and VANE, J. R. (1951), Lancet, $1,380$.

WILKINS, R. W', HALPERIN, $\mathbf{M}_{\text {. }} \mathbf{H}$., and LITTER, J. (I950), Circulation, 2, 373 .

WRIGHT, H. P., KUBIK, M. M., and HAYDEN, M. (1953)? Brit. med. F., 1, 1021. 